\title{
Histopathological spectrum and outcome of surgery for salivary gland tumors presented in tertiary care hospital of Pakistan.
}

1. MBBS, MS (General Surgery) Senior Registrar Surgery Mayo Hospital Lahore Pakistan. 2. MBBS, FCPS (General Surgery) Senior Registrar Surgery Mayo Hospital Lahore Pakistan.

3. MBBS, FCPS, FACS, FRCS,

MCPS-HPE

Professor and Head Surgery Mayo Hospital Lahore, Pakistan

4. MBBS, M.Phil (Biochemistry) Lecturer Biochemistry

King Edward Medical University, Lahore, Pakistan.

5. MBBS

Post Graduate Resident General Surgery

Mayo Hospital Lahore Pakistan.

6. MBBS

Post Graduate Resident General Surgery

Mayo Hospital Lahore Pakistan.

Correspondence Address:

Dr. Ahmed Siddique Ammar

Department of Surgery

Mayo Hospital Lahore Pakistan

asammar1912@gmail.com

Article received on:

23/12/2020

Accepted for publication:

15/02/2021
Ahmed Siddique Ammar ${ }^{1}$, Rizwan Khalid ${ }^{2}$, Syed Asghar Naqi ${ }^{3}$, Shehrbano Khattak ${ }^{4}$, Farwa Inayat ${ }^{5}$, Sohail Asghar ${ }^{6}$

ABSTARCT... Objective: This study is aimed to know the histopathological spectrum and outcome of surgery for salivary gland tumors presented in a tertiary care hospital of Pakistan. Study Design: Retrospective study. Setting: Tertiary Care Hospital of Pakistan. Period: July 2018 to June 2020. Material \& Methods: After approval from Institutional Review Board. Total 73 patients were selected with preoperative diagnosis of salivary gland tumors with consecutive non probability sampling. All surgical procedures were done by specialist general surgeons who had experience of more than 10 years of head and neck surgery. Results: Male to female ratio was 2:1 with mean age of patients was 46 years. Among males $29(59.1 \%)$ were benign salivary gland tumors while $20(40.81 \%)$ were malignant salivary gland tumors. Among females $13(54.16 \%)$ were benign and 11 (45.83\%) were malignant salivary gland tumors Most common benign tumor was pleomorphic adenoma 32 (43.8\%) while mucoepidermoid carcinoma was most common malignant tumor 17 (23.28\%). Only 9 (12.32\%) patients experienced nerve paresis. Conclusion: Male preponderance, a relatively younger age at presentation and single predominant benign tumor (pleomorphic adenoma) were the significant findings. Majority of them were found in parotid gland and found to be benign in nature. Majority of them were found in parotid gland and found to be benign in nature. Although fine needle aspiration cytology and magnetic resonance imaging provide some useful information about the nature of tumor but most of them will acquire a surgical excision in order to find the definitive diagnosis.

Key words: $\quad$ Facial Nerve Palsy, Mucoepidermoid Tumor, Malignancy, Pleomorphic Adenoma, Salivary Gland.

Article Citation: Ammar AS, Khalid R, Naqi SA, Khattak S, Inayat F, Asghar S. Histopathological spectrum and outcome of surgery for salivary gland tumors presented in tertiary care hospital of Pakistan. Professional Med $\mathrm{J}$ 2021; 28(10):1422-1427. https://doi.org/10.29309/TPMJ/2021.28.10.6293

\section{INTRODUCTION}

Parotid Submandibular and Sublingual salivary glands are considered as major salivary glands while there are numerous minor salivary glands which are located throughout the submucosa of upper aero digestive tract. ${ }^{1}$ Both types of malignancy either benign or malignant can occur in these salivary glands. The tumors of salivary glands are less than $1 \%$ of all the tumors of the body and $2 \%$ to $4 \%$ of all the head and neck tumors. $^{2}$ Worldwide the incidence of salivary gland tumors is reported from 0.4 to 14 cases per 100,000 person and the incidence of malignant salivary gland tumors ranges from 0.4 to 2.6 per 100,000 people. $^{3}$

The etiology of salivary gland tumors is multivariant. Use of tobacco, vitamin A deficiency, ionizing radiation, chemotherapy and prolonged exposure to the sunlight contribute to the development of the salivary gland tumors. Pleomorphic adenoma is the most common benign while mucoepidermoid carcinoma is the most common malignant tumor of salivary gland reported in the literature. ${ }^{4,5}$ Parotid gland is the most commonly involved by the malignancy in $80 \%$ of the cases while $10 \%$ to $20 \%$ of malignancy occurs in submandibular and sublingual glands. ${ }^{6}$ It has been reported that about one third of malignant parotid tumors involve the facial nerve while hypoglossal nerve and trigeminal nerves are most commonly involved in the tumors of submandibular and sublingual gland. ${ }^{7}$ 
The most common presenting feature of salivary gland tumors is a long-standing lump while there is rapid growth of lump in malignant conditions along with nerve involvement. ${ }^{8}$ First classification of salivary gland tumors was established by World Health Organization (WHO) in 1972 and after that many amendments has been done. Diagnosis of salivary gland tumors include combination of clinical features along with ultrasonography, sialography, computed tomography (CT), magnetic resonance imaging (MRI) and fine needle aspiration cytology (FNAC). ${ }^{9}$ However, differentiation between benign and malignant is difficult on the basis of FNAC. Benign tumors need excision with follow-up for recurrence while malignant tumors need excision along with removal of surrounding involved tissue, neck dissection followed by chemotherapy. ${ }^{10}$

The purpose of this study is to report the demographic details, Histological pattern of the disease and treatment outcome of salivary gland disorders in the patient population presenting in one of the biggest hospital of Pakistan.

\section{MATERIAL \& METHODS}

It was a retrospective study conducted in East Surgery Ward of Mayo Hospital Lahore Pakistan, King Edward Medical University (KEMU) Lahore Pakistan. The duration of study was 2 years, from $1^{\text {st }}$ July 2018 to $30^{\text {th }}$ June 2020 . This study was approved by the Institutional review board of King Edward Medical University. A total of 73 patients were selected for this study by consecutive non probability sampling technique. All those patients selected in this study were admitted patients in the surgical department through outdoor department with pre-operative diagnosis of salivary gland tumor of any type and were operated for these tumors. All surgeries were done by specialist general surgeons who had experience of more than 10 years of head and neck surgery. Patients with recurrent salivary gland tumors were excluded from the study.

All patients had detailed evaluation by complete history and physical examination followed by relevant investigations including Fine Needle Aspiration Cytology (FNAC) of all cases, Ultrasonography (USG) and computed tomography (CT) in selective cases where all other investigations were either inconclusive with the clinical diagnosis.

Prophylactic broad-spectrum antibiotics including three doses of injection amoxiclav were given intravenous at induction and continued for two more doses in all patients. Superficial conservative parotidectomy was employed for tumors of superficial lobe of the parotid gland while the tumors of deep lobe total conservative parotidectomy was done. No specific nerve detection technology was used. Pathologies of submandibular and sublingual gland were treated with appropriate excision biopsies and the relevant nerves were saved by employing the standard techniques recommended for the flaps and dissection during resection. A low vacuum suction drain was kept in all cases after excision surgery and was removed on second or third post-operative day when discharge was reduced to less than $5 \mathrm{ml}$ per day in 24 hours. Skin sutures were removed on $5^{\text {th }}$ post-operative day. For the purpose of study facial nerve paresis was defined as temporary loss of nerve function gaining substantial or complete recovery in six months' time.

Facial nerve damage was defined as documented or inadvertent damage to the nerve resulting in permanent loss of nerve function. Surgical site infection was defined as the presence or absence of seroma or hematoma beneath the skin. Flap necrosis was defined as necrosis of flap which was treated with surgical debridement and repair. All excised specimen was sent to the histopathology department of King Edward Medical University to report the nature of the disease. All those patients with confirmed tumors on histopathology report were followed initially every month for first six months and then every six months. No specific measure was taken apart from physiotherapy was adopted for transient nerve paresis. The quantitative data was analyzed using SPSS version 26.

\section{RESULTS}

Out of total 73 patients operated for salivary gland 
tumors $49(67.12 \%)$ were male and 24 (32.8\%) were female. Among males 29 (59.1\%) were benign salivary gland tumors while 20 (40.81\%) were malignant salivary gland tumors. Among females 13 (54.16\%) were benign and 11 (45.83\%) were malignant salivary gland tumors (Table-I). The male to female ratio was 2:1. The mean age of patients was 46 years with minimum age of 28 years for benign Salivary gland tumors and 32 years for malignant salivary gland tumors. 52 patients had tumor of right parotid gland while 21 had tumor of left parotid gland. Among histology pleomorphic tumor was the most common benign tumor present in about 32 (43.8\%) of cases while mucoepidermoid carcinoma was the most common malignant tumor observed in about 17 (23.28\%) of cases (Table-II). Regarding tumor size most of the patients had tumor size of more than $4 \mathrm{~cm}$. Regarding post-operative complications, only $9(12.32 \%)$ patients experienced nerve paresis (Table-III).

\begin{tabular}{|c|c|c|}
\hline Age Group & Male & Female \\
\hline $\begin{array}{l}20-30 \\
\text { Years }\end{array}$ & $\begin{array}{c}3(6.12 \%) B=3 \\
M=0\end{array}$ & $\begin{array}{c}1(4.16 \%) B=1 \\
M=0\end{array}$ \\
\hline $\begin{array}{l}31-40 \\
\text { Years }\end{array}$ & $\begin{array}{c}8(16.3 \%) B=6 \\
M=2\end{array}$ & $\begin{array}{c}5(20.83 \%) B=4 \\
M=1\end{array}$ \\
\hline $\begin{array}{l}41-50 \\
\text { Years }\end{array}$ & $\begin{array}{c}13(26.5 \%) B=9 \\
M=4\end{array}$ & $\begin{array}{c}9(37.5 \%) B=4 \\
M=5\end{array}$ \\
\hline $\begin{array}{l}51-60 \\
\text { Years }\end{array}$ & $\begin{array}{c}18(36.73 \%) B=7 \\
M=11\end{array}$ & $\begin{array}{c}6(25 \%) B=2 \\
M=4\end{array}$ \\
\hline $\begin{array}{l}61-70 \\
\text { Years }\end{array}$ & $\begin{array}{c}06(12.24 \%) \quad B=3 \\
M=3\end{array}$ & $\begin{array}{c}3(12.5 \%) B=2 \\
M=1\end{array}$ \\
\hline $\begin{array}{l}71-80 \\
\text { Years }\end{array}$ & $\begin{array}{c}01(\%) B=1 \\
M=0\end{array}$ & $\begin{array}{c}0(\%) B=0 \\
M=0\end{array}$ \\
\hline Total & $\begin{array}{c}49(67.12 \%) \\
B=29(59.1 \%) \\
M=20(40.81 \%)\end{array}$ & $\begin{array}{c}24(32.8 \%) \\
B=13(54.16 \%) \\
M=11(45.83 \%)\end{array}$ \\
\hline
\end{tabular}

\begin{tabular}{|c|c|c|c|c|c|}
\hline \multirow{3}{*}{ Type of Tumor } & Parotid Gland & $\begin{array}{c}\text { Submandibular } \\
\text { Gland }\end{array}$ & $\begin{array}{c}\text { Sublingual } \\
\text { Gland }\end{array}$ & No of Patients \\
\hline \multirow{4}{*}{ Benign } & Myoepithelioma & 1 & 0 & 0 & $1(1.36 \%)$ \\
\cline { 2 - 6 } & Pleomorphic Adenoma & 25 & 7 & 0 & $32(43.8 \%)$ \\
\cline { 2 - 6 } & Warthin Tumor & 2 & 2 & 0 & $4(5.47 \%)$ \\
\cline { 2 - 6 } & Oncocytoma & 1 & 1 & 0 & $2(2.73 \%)$ \\
\hline \multirow{4}{*}{ Malignant } & Lymphadenoma & 2 & 0 & 1 & $3(4.10 \%)$ \\
\hline & Total Benign & $31(73.8 \%)$ & $10(23.8 \%)$ & $1(2.28 \%)$ & $42(57.53 \%)$ \\
\hline & Adenocarcinoma & 2 & 0 & 0 & $2(2.73 \%)$ \\
\cline { 2 - 6 } & Clear Cell Carcinoma & 2 & 1 & 0 & $3(4.10 \%)$ \\
\cline { 2 - 6 } & Acinic cell Carcinoma & 4 & 2 & 1 & $7(9.58 \%)$ \\
\cline { 2 - 6 } & Mucoepidermoid carcinoma & 10 & 7 & 1 & $2(2.73 \%)$ \\
\cline { 2 - 6 } & Salivary duct carcinoma & & 1 & $23.28 \%)$ \\
\cline { 2 - 6 } & Total Malignant & $18(58.06 \%)$ & $11(35.4 \%)$ & $2(6.45 \%)$ & $31(42.4 \%)$ \\
\cline { 2 - 6 } & Total & $49(67.12 \%)$ & $21(28.76 \%)$ & $3(4.10 \%)$ & 73 \\
\hline
\end{tabular}

Table-II. Histopathalogy of different types of salivery gland tumors.

Post-Operative Complications

None

Nerve Paresis

Surgical Site Infection

Flap necrosis

Nerve Damage
No of Cases and Percentage

\begin{tabular}{c}
$54(73.97 \%)$ \\
\hline $9(12.32 \%)$ \\
\hline $3(4.10 \%)$ \\
\hline $7(16.2 \%)$ \\
$0(0.00 \%)$
\end{tabular}

$54(73.97 \%)$

$3(4.10 \%)$

$0(0.00 \%)$

Table-III. Complications during salivary gland tumor surgery.

\section{DISCUSSION}

Salivary gland disorders are a distinct group of disorders which affect both major and minor glands. These disorders range from inflammatory changes, granulomatous disorders, autoimmune diseases, obstructive, developmental, idiopathic and neoplastic disorders. ${ }^{11}$ Salivary gland tumors are not a common presentation in any outdoor department of a tertiary care hospital. These tumors include both benign and malignant 
types. $^{12}$ The epidemiology of salivary gland tumors in Pakistan is not well documented and only a limited number of research articles based on histological pattern of salivary gland tumors are present in literature. ${ }^{13}$

In this study, the minimum age for benign salivary gland tumor was found to be 28 years of age while for malignant salivary gland tumor it is 32 years of age. Another study done by Khan $\mathrm{HU}$ et al also showed that relatively younger patients with mean age of 34 were affected by the disorders of salivary gland. ${ }^{14}$ Findings of salivary gland tumors in younger patients were also found in study done by Shrestha and associates ( 44.8 years) and by Ashkavandi and colleagues (41.8 years). ${ }^{15,16}$ In our study there was male predominance of salivary gland tumors (2:1). This male predominance was in consistent with the findings observed by Seethala et al. On the other hand there are some studies done by Rewsawan et al who showed female predominance of salivary gland tumors. ${ }^{17}$ In this study it was found that females had salivary gland tumors in their $4^{\text {th }}$ decade of life while males have these tumors in $5^{\text {th }}$ decade of life. Razek et al found most of the salivary gland tumors in $3^{\text {rd }}$ decade of life followed by $4^{\text {th }}$ decade in his study. ${ }^{18}$

In our study the ratio between benign and malignant salivary gland tumors in males were found to be $1.45: 1$ while in females this ratio was 1.18:1. This ratio is almost same in both genders showing that both males and females can have benign and malignant salivary gland tumors and gender has no role in type of tumor.Bobati et al also showed that benign salivary gland tumors were more common in age group of 31 to 40 years and malignancy was reported was predominant in the $5^{\text {th }}$ decade and the male to female ratio was found to be $1.7: 1 .{ }^{19}$

In this study pleomorphic adenoma was the most common benign salivary gland tumor 32 (43.8\%) followed by Warthin tumor 4 (5.47\%). Most of the cases of pleomorphic adenoma were found in parotid gland (73.8\%) while lingual salivary gland was least affected by all types of salivary gland tumors. This finding is endorsed in many case series available which showed that pleomorphic adenoma is the most common salivary gland tumor and most cases of it are found in parotid gland..$^{20,21}$

Mucoepidermoid carcinoma was the most commonly found malignant carcinoma in the salivary gland $17(23.28 \%)$ and most of this carcinoma was found in parotid gland. Other studies also showed that the most common malignant tumor found in salivary gland is mucoepidermoid carcinoma and it is most commonly found in parotid gland. ${ }^{22}$ It mostly affects women slightly higher as compared to men with peak age of $5^{\text {th }}$ decade. Nerve involvement is not seen in low grade tumor while it is quite common in high grade tumor.in this study total 17 mucoepidermoid tumors were encountered out of which 10 were found in parotid gland while 7 were found in submandibular gland.

Transient facial nerve palsy (12.32\%) following parotid gland surgery in this study is well within the reports of $1.6 \%$ to $33.3 \%$ reported by national and international studies. ${ }^{24,25}$ Other complication like surgical site infection and flap necrosis are also consistent with the international studies. ${ }^{25}$

There exist some limitations to this study. Firstly, the sample size is small as compared to large multicenter studies to interpret the true load of disease in our setup. Secondly this was a single center study and more multicentric studies are required to evaluate the true burden of salivary gland tumors in Pakistan.

\section{CONCLUSION}

This study highlights the spectrum of salivary gland pathologies in a large tertiary care hospital of Pakistan. Male preponderance, a relatively younger age at presentation and single predominant benign tumor (pleomorphic adenoma) were the significant findings. Most of the salivary gland tumors present as painless enlarging masses. Majority of them were found in parotid gland and found to be benign in nature. Although fine needle aspiration cytology and magnetic resonance imaging provide some useful information about the nature of tumor but most of them will acquire a surgical excision in 
order to find the definitive diagnosis.

Copyright(C) 15 Feb, 2021.

\section{REFERENCES}

1. Attyé A, Troprès I, Rouchy RC, Righini C, Espinoza S, Kastler A, et al. Diffusion MRI: literature review in salivary gland tumors. $2017 ; 23(5): 572-5$.

2. Ronchi A, Montella M, Zito Marino F, Panarese I, Pagliuca F, Colella G, et al. Diagnostic accuracy of FNA cytology for diagnosis of salivary gland tumors in pediatric patients. 2019; 127(8):529-38.

Chen AA, Gheit T, Stellin M, Lupato V, Spinato G, Fuson $R$, et al. Oncogenic DNA viruses found in salivary gland tumors. 2017; 75:106-10.

4. da Silva LP, Serpa MS, Viveiros SK, Sena DAC, de Carvalho Pinho RF, de Abreu Guimarães LD, et al. Salivary gland tumors in a Brazilian population: A 20-year retrospective and multicentric study of 2292 cases. 2018; 46(12):2227-33.

5. Denaro M, Navari E, Ugolini C, Seccia V, Donati V, Casani AP, et al. A microRNA signature for the differential diagnosis of salivary gland tumors. 2019; 14(1):e0210968.

6. Faquin WCJCC. Diagnosis and grading of basaloid salivary gland tumors using the milan system for reporting salivary gland cytopathology. 2020; 128(2):87-8.

7. Haeggblom L, Ursu RG, Mirzaie L, Attoff T, Gahm C, Nordenvall LH, et al. No evidence for human papillomavirus having a causal role in salivary gland tumors. 2018; 13(1):44.

8. Harada K, Ferdous T, Ueyama YJBc. PD-L1 expression in malignant salivary gland tumors. 2018; 18(1):156.

9. Skalova A, Michal M, Simpson RHJMP. Newly described salivary gland tumors. 2017; 30(1):S27-S43.

10. Skálová $A$, Stenman $G$, Simpson $R H$, Hellquist $H$, Slouka D, Svoboda $T$, et al. The role of molecular testing in the differential diagnosis of salivary gland carcinomas. 2018; 42(2):e11-e27.

11. Park W, Bae H, Park MH, Hwang NY, Sohn I, Cho J, et al. Risk of high $\square$ grade malignancy in parotid gland tumors as classified by the Milan System for Reporting Salivary Gland Cytopathology. 2019; 48(3):222-31.

12. Seethala RRJSPC. Salivary gland tumors: Current concepts and controversies. 2017; 10(1):155-76.
13. Schvartsman G, Pinto NA, Bell D, Ferrarotto RJH, Neck. Salivary gland tumors: Molecular characterization and therapeutic advances for metastatic disease. 2019; $41(1): 239-47$.

14. Khan Hu, Khalid K, Yousuf ElJJOFJMU. Spectrum of Salivary Gland Disorders at a Tertiary Care Hospital in Central Lahore. 2017; 11(3).

15. Shrestha S, Pandey G, Pun C, Bhatta R, Shahi RJJoPoN. Histopathological pattern of salivary gland tumors. $2014 ; 4(7): 520-4$.

16. Jaafari-Ashkavandi Z, Ashraf M-J, Moshaverinia MJAPJCP. Salivary gland tumors: A clinicopathologic study of 366 cases in southern Iran. 2013; 14(1):2730.

17. Rewsuwan S, Settakorn J, Mahanupab PJCMMB. Salivary gland tumors in Maharaj Nakorn Chiang Mai Hospital: A retrospective study of 198 cases. 2006; 45(2):45-3.

18. Razek AAKA, Mukherji SKJNC. Imaging of posttreatment salivary gland tumors. 2018; 28(2):199208.

19. Bobati SS, Patil B, Dombale VJJoo, JOMFP mp. Histopathological study of salivary gland tumors. $2017 ; 21(1): 46$.

20. Sando Z, Fokouo JV, Mebada AO, Djomou F, NDjolo A, Oyono JLEJPAMJ. Epidemiological and histopathological patterns of salivary gland tumors in Cameroon. 2016; 23: 66.

21. Seethala RR, Griffith CCJSpc. Molecular pathology: Predictive, prognostic, and diagnostic markers in salivary gland tumors. 2016; 9(3):339-52.

22. Romano EB, Wagner JM, Alleman AM, Zhao L, Conrad $\mathrm{RD}$, Krempl GAJTL. Fine $\square$ needle aspiration with selective use of core needle biopsy of major salivary gland tumors. 2017; 127(11):2522-7.

23. Griffith CC, Siddiqui MT, Schmitt ACJDC. A ncillary testing strategies in salivary gland aspiration cytology: A practical pattern $\square$ based approach. 2017; 45(9):808-19.

24. Bashir N, Iqbal F, Khan MM, Sharif NJPO, Journal D. Estrogen receptor? Expression in salivary gland tumors. 2018; 38(2):160-3.

25. Griffith CC, Schmitt AC, Little JL, Magliocca KRJAop, medicine I. New developments in salivary gland pathology: Clinically useful ancillary testing and new potentially targetable molecular alterations. 2017; $141(3): 381-95$. 


\begin{tabular}{|c|c|c|c|}
\hline \multicolumn{4}{|c|}{ AUTHORSHIP AND CONTRIBUTION DECLARATION } \\
\hline Sr. \# & Author(s) Full Name & Contribution to the paper & Author(s) Signature \\
\hline 1 & Ahmed Siddique Ammar & \multirow{7}{*}{$\begin{array}{l}\text { Substantial contribution to the } \\
\text { conception and design of the work. } \\
\text { Drafting the work. Final approval } \\
\text { of the version to be published and } \\
\text { agreement to be accountable for all } \\
\text { aspects of the work in ensuring that } \\
\text { questions related to the accuracy } \\
\text { or integrity of any parts of the work } \\
\text { are appropriately investigated and } \\
\text { resolved. }\end{array}$} & \\
\hline 2 & Rizwan Khalid & & \\
\hline 2 & Rizwan nnalla & & \\
\hline 3 & Syed Asghar Naqi & & \\
\hline 4 & Shehrbano Khattak & & \\
\hline 5 & Farwa Inayat & & \\
\hline 6 & Sohail Asghar & & \\
\hline
\end{tabular}

